\title{
Histórias de corpos e caminhos: memória e narrativa oral com adolescentes
}

\author{
Ana Julia Toledo Netto \\ DOI 10.20396/eha.vil4.3451
}

Esta comunicação é um recorte de uma pesquisa mais ampla realizada durante o Mestrado em Ensino de Artes Cênicas, pela UFMG, em uma escola pública de zona rural situada nos arredores da cidade de Juiz De Fora, MG. Propondo uma educação voltada para a sensibilidade, visou relacionar a prática da contação de histórias com o desenvolvimento estésico e estético de 15 adolescentes de 11 a 15 anos.

O solo da pesquisa se configurou a partir do trabalho em oficinas de contação de histórias, nas quais a ludicidade e a estesia foram o fulcro para o desenvolvimento das atividades com os discentes. Através de princípios da metodologia de pesquisa-ação, buscou-se um trabalho mais dialógico, centrado na experiência dos adolescentes, com propostas de atividades que enfatizassem a corporeidade, a estimulação perceptiva e a auto escuta.

Entendo como objetivo da educação estética não somente oferecer aos discentes textos reconhecidos ou músicas conceituadas e outras obras de arte, mas o contato direto com o que Duarte Júnior (2000) propõe: uma educação estésica/estética voltada para a vida mesma. Ao emprego metodológico de exercícios e jogos que enfatizassem os processos perceptivos como forma de suscitar imagens e a criação em contação de histórias, encontrei nas narrativas dos adolescentes não apenas suas memórias pessoais, mas percepções coletivas do imaginário de um lugar. Ver, cheirar, apalpar, enfim sentir a materialidade do mundo, que a princípio parece apenas ser um processo biológico, são as portas de entrada para o conhecimento, seus meios de interação, comunicação e criação na cultura da qual fazem parte.

As atividades que pretendo destacar nesse relato relacionam-se com a memória sensorial dos alunos pela relação de intercorporeidade com os espaços, seres e representações da localidade e foi uma das primeiras experiências que propus ao grupo, no início do ano letivo. A partir da estratégia dos caminhos de Ilo Krugli para o Teatro Ventoforte, descrito por Nogueira ${ }^{2}$ propus experiên-

1 Mestre em Ensino de Artes Cênicas pela UFMG, professora de artes em escolas públicas de Juiz de Fora (MG).

2 NOGUEIRA, 2008, 2015. 
cias de observação e simbolização das sensações físicas dos caminhos percorridos pelos adolescentes de casa até à escola, e a coleta de causos, histórias e anedotas junto aos familiares, como jovens etnógrafos.

O povoado onde está situada a escola, apesar da proximidade com o centro urbano, guarda ainda algumas características de zona rural, ou seja: fazendas no entorno, alunos que vêm de distrito vizinho e arredores em veículo escolar e ainda que trabalham no cultivo agrícola ou na pecuária. A TV e o rádio ainda são os mais presentes meios de comunicação na comunidade, e mesmo com a baixa qualidade do sinal de internet, muitos alunos têm seus celulares e passam grande parte do tempo envolvidos com esse dispositivo de comunicação. Apesar de muitos de seus costumes e histórias estarem sendo esquecidos, a conversa desses adolescentes ainda é recheada de crendices, histórias e personagens míticos e sobrenaturais.

\section{As histórias que os corpos contam}

Comumente ao se falar em educação para a preservação patrimonial logo se têm em mente visitas a museus, construções, apreciação e análise de objetos antigos, contudo o imaginário, os saberes, os modos de ver e fazer no mundo são também patrimônio de um povo, de uma localidade. Patrimônios que estão vivos no dia a dia dos habitantes de um lugar. Quanto da memória de uma comunidade não está contida em uma antiga receita de um bolo feito pela avó, numa cantiga de ninar, numa anedota sobre um morador antigo, numa reza ou numa simpatia? Simples fazeres cotidianos que se preservam pela oralidade.

Assim a cultura de uma localidade, de um povo não é um conjunto de coisas, artefatos e costumes estanques, como algo acabado. É algo vivo que afeta o indivíduo e é afetado pelas decorrências a ele, simultânea e continuamente. De acordo com Greiner [...] "não é a cultura que influencia o corpo ou o corpo que influencia a cultura. Trata-se de uma espécie de "contaminação" simultânea entre dois sistemas sígnicos onde ambos trocam informações de modo a evoluir em processo juntos". A partir desse pensamento podemos avaliar que cada indivíduo contém em seu corpo seus traços de vida, memórias e particularidades que formam um todo subjetivo, numa relação constante com sua cultura, absorvendo e sendo absorvido, num processo contínuo entre o coletivo e o particular, dentro e fora dos sujeitos.

3 GREINER, 2005, p. 104. 
Ainda segundo Greiner não pode haver conhecimento sem que haja mobilidade e deslocamento: [...] "O conhecimento vem do movimento, tanto do movimento do corpo como dos objetos moventes que fazem parte do entorno" " Toda percepção é, pois, resultado do movimento corpóreo, da motricidade do corpo em um emaranhado com o mundo. Desse modo, educação estética e corporeidade estão intimamente relacionadas, é através da experiência sensível dos nossos sentidos interagindo com o mundo que desenvolvemos nossa percepção, refinamos nossa sensibilidade e construímos conhecimentos. É pela "ocup-ação" do corpo no tempo e no espaço que construímos nossos saberes (e sabores).

No intuito de criar espaços de abertura aos sentimentos e memórias afetivas dos discentes de maneira a possibilitar, também, um diálogo com a cultura local, com os modos de viver da comunidade, uma das primeiras experiências que propus ao grupo, no início do ano letivo, foi inspirada na estratégia dos caminhos de Ilo Krugli ${ }^{5}$ para Teatro Ventoforte no trabalho com teatro em comunidades. Esse procedimento abriu e fechou os trabalhos desenvolvidos com os alunos durante o ano.

Essa proposta inspirou o mapeamento dos caminhos da comunidade e das experiências perceptivas dos alunos, consistindo na observação e representação, por meio de gestos e desenhos das sensações físicas sentidas pelos caminhos percorridos na comunidade de casa até à escola. Meu objetivo era aguçar-lhes os sentidos e levá-los a se aterem a detalhes que, muitas vezes, passam despercebidos pelo corpo acostumado ao cotidiano, além de trazer a atenção deles para os efeitos provocados no corpo pela estesia.

Inicialmente, propus a turma que no caminho percorrido de volta para casa prestassem atenção nas sensações percebidas durante o caminhar. Quais os lugares mais iluminados e os mais escuros, quais cheiros, tipos de relevos, barulhos, movimentos de pessoas ou animais? $\mathrm{Na}$ aula seguinte, após os primeiros exercícios de caminhada pelo espaço, pedi que se deitassem no chão. Ao som de uma música ambiente para auxiliar no relaxamento, de olhos fechados, os alunos deveriam imaginar-se acordando em casa e fazendo o que normalmente fazem em dia letivo. Depois deveriam fazer corporalmente o percurso de casa para a escola, e à medida que fossem lembrando deveria executar os movimentos trazendo para o corpo a memória sensorial desses caminhos.

Após essa vivência, sentamos em círculo, em volta de um tecido de lona crua com fotos da

\footnotetext{
4 GREINER, 2010, p. 90.

5 Marcia P. Nogueira descreve em diversas publicações a proposta dos caminhos como estratégia na abertura dos trabalhos em comunidades, com intuito de resgatar histórias pessoais e coletivas, trazendo o reconhecimento dos locais onde estão situadas as histórias. Segundo Nogueira llo Krugli compara contar histórias com os caminhos:" [...] Um mesmo começo, meio e fim. Cada caminho é, na verdade uma história, simboliza uma experiência de vida." (Nogueira, 2008 b, p. 124).
} 
escola no meio. Os alunos deveriam posicionar-se em torno e desenhar cada um o caminho feito todos os dias de casa para escola, evidenciando as sensações percebidas. Como Nogueira ${ }^{6}$ aponta: “[...] Esta sensibilização sensorial que antecede os desenhos permite um aprofundamento dos trabalhos. De um lado se aciona a memória, de outro a imaginação".

A partir dos caminhos desenhados por cada aluno tivemos o mapa de quase todo o povoado. Analisamos o conjunto: as ruas, os lugares onde os caminhos se encontravam, as residências e os desafios e prazeres que cada caminho oferecia diariamente a eles. Desse modo algumas das particularidades que constituem a pequena comunidade iam sendo retratadas pelas expressões daqueles adolescentes. Percebi que ali estavam as percepções de cada aluno e suas interpretações pessoais do universo em que vivem e circulam diariamente. Essa proposta pôde trazer um reconhecimento de si dentro da comunidade, ao mesmo tempo em que os aproximaram de seus pares.

Ainda que indivíduos de uma comunidade compartilhem lembranças comuns, a memória do indivíduo se constrói singular e subjetiva, pois, mesmo que várias pessoas façam quase o mesmo trajeto todos os dias, a cada um esse mesmo caminho produzirá diferentes sensações e diferente memória sensorial ficará como que impressa no corpo. Como analisa Le Breton7, existe um bosque para cada ser que por ele caminha, pois os indivíduos não são sensibilizados pelas mesmas características que o bosque apresenta.

Mil florestas em uma, mil verdades do mesmo mistério que se esvai e é dado apenas fragmentariamente. Não há verdade da floresta, mas uma multiplicidade de percepções sobre ela, de acordo com os ângulos de foco, expectativas, pertenças sociais e culturais. ${ }^{8}$

Assim também como Collot (2015) observa é no entrelaçamento homem e mundo, possibilitado pelo corpo, instrumento da percepção, que se encontra a fonte do discurso do sujeito. Seja sua fala subjetiva, ou artística, expressa na poesia, na arte, na sua relação com o mundo.

A paisagem está mais ligada ao ponto de vista de um indivíduo, indivíduo a quem o horizonte, ao mesmo tempo, limita e abre para o invisível. Ela confere ao mundo um sentido que não é mais subordinado a uma crença religiosa coletiva, mas, sim, o produto de uma experiência individual, sensorial e suscetível de uma elaboração estética singular?

\footnotetext{
6 Ibidem, p. 123.

7 LE BRETON, 2007, p. 12

8 Tradução minha: "Mil bosques en uno solo, mil verdades de un mismo misterio que se escabulle y que sólo se entrega fragmentariamente. No existe verdad del bosque, sino una multitud de percepciones sobre el mismo, según los ángulos de enfoque, las expectativas, las pertenencias sociales y culturales".

9 COLLOT, 2015, p. 18
} 
A paisagem, não limitada ao sentido da visão, é percebida em toda dimensão do aparelho perceptivo humano, não como espetáculo exterior ao indivíduo, mas o abraçando e envolvendo. O corpo/território, o corpo/memória tem em si gravado as formas, as experiências e as relações de intercorporeidade. Além de que o sujeito carrega de significados particulares os ambientes em que interage. Assim como cada corpo guarda em si as histórias vividas e imaginadas, os desenhos desses adolescentes, suas falas, histórias e representações seriam as expressões do que foi percebido e construído em seus corpos em relação de reciprocidade com o mundo e com os outros.

\section{As histórias que os caminhos contam}

Objetivando uma construção dialógica, centrada na experiência, cada aluno recebera um pequeno caderno espiral, que daria corpo a um tipo de registro inspirado no diário de itinerância proposto por Barbier (2007), uma mistura de relato de experiências e relato íntimo. Nesses cadernos os alunos anotaram sentimentos, experiências e reflexões após as aulas e também antigas histórias, causos e anedotas locais nas pesquisas, que relato a seguir.

Apesar de receberem diversas influências das mídias e manterem assuntos que caracterizam a faixa etária, esses adolescentes têm presentes em suas conversas inúmeras referências das crendices locais, histórias familiares e de assombração. Assim eles relatam: "Minha avó conta que naquele tempo na Rua dos Coqueiros...", ou "Na Curva do Desengano tem um cavaleiro negro que aparece toda quaresma", ou ainda "E passando em frente à fábrica, minha prima viu passar o vulto do homem carregando a mulher viva dentro do caixão...".

Essas conversas tecidas nos seios das famílias e pelas esquinas, nas quais histórias individuais e coletivas se entrelaçam, reelaboram a memória das duas pequenas localidades em que vivem. Esse universo mítico é recheado por causos e figuras que são próprios dessas comunidades, embora comumente seja entrecruzado por lendas brasileiras, ou mesmo figuras de novelas, como, por exemplo, o "Cadeirudo", personagem da novela Tieta da Rede Clobo. Não obstante o fato de ser um personagem famoso de novela, não retira a credibilidade e a veracidade com que é narrada. Os discentes acreditam mesmo na existência desse personagem que aparece pelas ruas dos povoados em noite escuras.

Com intuito de trazer para as aulas a riqueza desse universo, propus aos alunos uma pesquisa dessas histórias junto aos familiares e membros da comunidade. Essa investigação parte do princípio de que a cultura é algo vivo em contínua relação com os corpos, em um trânsito entre as ações 
coletivas e individuais, pois, como Greiner ${ }^{10}$ define, a cultura é construída "[...] no trânsito entre o individual e o coletivo, entre o dentro e o fora do corpo, operando o tempo inteiro num continuum entre emoção, razão, ação corpórea incluindo aptidão para a conceituação".

As histórias de uma localidade, seu imaginário e seus fazeres como sendo processualmente reconstruídos pelas relações cotidianas, pela intercorporeidade de seus habitantes. Portanto, a cultura, presente dentro e fora dos sujeitos, se expressa nos modos dos corpos, nas falas, no imaginário, no sentir e pensar. Para reforçar esse pensamento, Greiner "1"utiliza a expressão "contaminação simultânea entre os dois sistemas" portanto, o corpo não está fechado em si mesmo, mas permanentemente interagindo, afetando e sendo afetado pelo ambiente.

Eis aqui algumas das histórias coletadas pelos alunos:

"Teve um dia que o meu pai disse que o patrão do meu avô era muito ruim que fazia mal para os outros e os animais. Meu pai disse que, quando ele morreu que ninguém foi ao enterro dele, aí disse que ele ficava vagando pela rua falando que ia se vingar de todos. Teve um dia que o trator da fazenda começou a andar sozinho, quando meu avô foi ver não tinha ninguém e no outro dia apareceu um monte de animal morto."

"Meu pai conta que quando ele era criança, ele ajudava seu tio cuidando da fazenda "Garanjanga", onde foi nascido e criado. Enquanto seu tio cortava capim para dar para os bois, meu pai ia pegar comida para eles, e o tio dele ficava cortando o capim. Quando ele voltava com a comida, ao se aproximar sempre escutava assovios de duas pessoas e ele ficava se perguntando quem ficava lá com seu tio...Um dia ele pensou que se chegasse mais rápido ia ver quem ficava lá assoviando. Ele chegou mais cedo e viu que junto com seu tio, ficava uma cobra, que com o tempo virou "amiga" do seu tio".

As histórias pesquisadas foram lidas ou contadas por cada aluno dentro do grupo. Em uma aula posterior, eu levei novamente para a turma o "Mapa das Sensações dos Nossos Caminhos", feito no início do ano letivo, para que cada um localizasse nos caminhos, os lugares onde essas histórias haviam ocorrido. Em qual local aconteceu tal história? Ou em que rua aparece o tal personagem? A partir dessa localização, cada aluno ilustrou a história pesquisada dentro do mapa. Agora era também o "Mapa Das Histórias De Nossos Caminhos". Além de configurar as sensações dos caminhos percorridos, também passou a ser o mapa mitológico da comunidade, segundo as pesquisas e experiências perceptivas da turma.

Após essa etapa, foram votadas as histórias que serviriam para serem contadas e duas delas 
foram escolhidas. Uma delas é sobre uma propriedade que, há algum tempo, era um hotel fazenda na comunidade. Trabalhamos o texto juntos para poder contar. Transcrevo-o aqui:

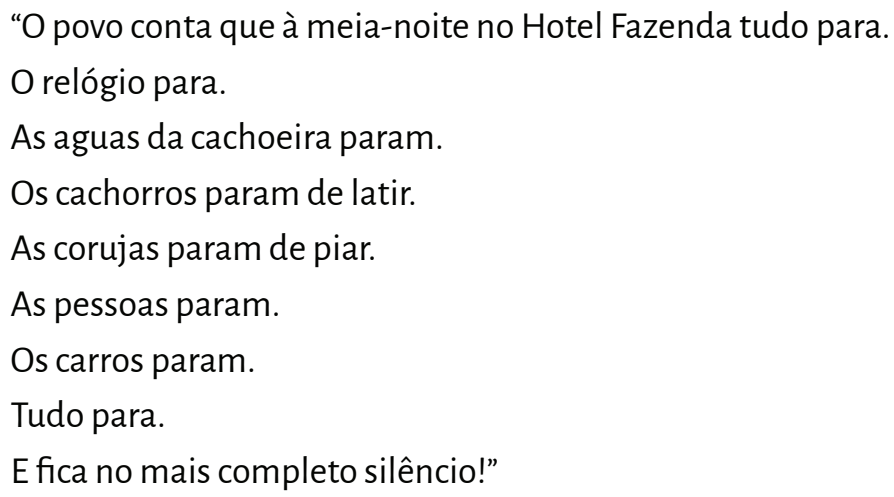

Essa história era contada por todos e a cada frase dita por um aluno, soava uma badalada, em um suposto relógio, na verdade um toque no triângulo, instrumento escolhido por eles para a sonoplastia. Quando soava a décima segunda badalada, os alunos contadores se entreolhavam assustados e, após uns segundos de silêncio, saíam correndo e gritando com medo desse congelamento do tempo, dos animais e das pessoas no hotel fazenda. Esta parte era a preferida pela turma.

A seleção do material para a contação de histórias, culminância de todo o trabalho desenvolvido, teve a participação dos alunos, tanto pelos textos trazidos por eles quanto na escolha dos contos de tradição. Foi resultado das muitas conversas, das pesquisas feitas e, também, emergiu de alguns jogos. As experiências vividas junto com as pesquisas serviram como retalhos que viemos costurando pelo fio dialógico que nos conduziu na busca pela interação dos alunos e a cultura da comunidade. Além de trazer sentimento de pertença e afirmação, pôde contribuir no fortalecimento da identidade dos próprios sujeitos dentro da localidade.

\section{Considerações Finais}

A partir do trabalho aqui relatado observo que a beleza contida nas histórias, no imaginário da coletividade, pode trazer maior valorização das narrativas orais como fontes para a construção de conhecimentos. O resgate da oralidade de uma comunidade, contida na memória do homem simples, que cotidianamente é calado pelas mídias de consumo e historicamente vem sendo ignorado por tantos séculos, pode ser entendida também como educação patrimonial. Trazer para a escola temas do cotidiano e da vivência desses alunos pode vir a funcionar como uma alavanca para a busca pela cidadania e resgate da autoestima. 
Segundo Azevedo"12 "Tocar as próprias raízes fundamenta a criação". A memória sensorial pode produzir cartografias, conduzindo experiências estéticas profundas e significativas dentro do contexto artístico e educacional. Basicamente nossa memória é originária das vivências sensoriais: os cheiros da infância, da comida perfumando a casa, das ruas, o perfume da pessoa amada. Trazer para o corpo essas memórias potencializa a criação estética, como um chão de onde partimos para alcançar o outro.

O corpo esse complexo que recebe constantemente sensações variadas em suas intensidades e manifestações, por ser único, em cada indivíduo, recebe e interpreta esses estímulos à sua maneira. De modo que as leituras sejam também diferentes e diretamente vinculadas às referências pessoais, revelando as subjetividades e seus vínculos consigo mesmo, nas mais amplas dimensões de sentidos.

Esse movimento dialético do sentir (receber e externalizar) é o que permite o indivíduo apreender sobre o mundo que o rodeia, e está intimamente limitado às suas condições perceptivas, as quais são definidas tanto por sua estrutura física e corporal quanto pelo contexto social e cultural. O corpo, matéria simbólica, produtor de sentido, produz cultura, ao mesmo tempo em que é afetado por ela, em um movimento contínuo e dialógico.

O trabalho com um olhar etnográfico dentro do ensino de arte pode aproximar comunidade e discente, trazendo reconhecimento de si e do entorno. Além de possuir caráter de resistência em face à crescente homogeneização, ao "assujeitamento" decorrente das mídias de consumo, cujo propósito parece ser o de transformar a todos numa massa uniforme e sem rosto.

\footnotetext{
12 AZEVEDO, 2014, s/p.
} 


\section{Referências Bibliográficas}

AZEVEDO, Sonia. Memória: criação e recepção nas artes da presença. In: Anais do VII Congresso ABRACE, TEMPOS DE MEMORIA: Vestígios, Ressonâncias e Mutações. Porto alegre: 2014.

BARBIER, Renée. A pesquisa-ação. Tradução de Lucie Didio. Brasília: Liber Livro Editora, 2007.

COLLOT, Michel. POESIA, PAISAGEM E SENSAÇÃO. In: Revista de Letras. - NO. 34 - Vol. (1) - jan./jun. - 2015.

DUARTE, João Francisco Jr. O Sentido Dos Sentidos: A Educação (Do) Sensível. Dissertação apresentada ao curso de Pós-Graduação em Educação da Universidade Estadual de Campinas, 234 p., 2000.

GREINER, Christine. O Corpo. Pistas para Estudos Interdisciplinares. São Paulo: Annablume, 2005.

O corpo em crise: novas pistas e o curto-circuito das representações. São Paulo: Annablume, 2010.

LE BRETON, David. Antropologia dos sentidos. Petrópolis: Vozes, 2017.

El sabor del mundo. Una antropologia de los sentidos - l' ed. - Buenos Aires: Nueva Visión, 2007.

MERLEAU-PONTY, Maurice. Fenomenologia da percepção. 4. ed. São Paulo: Editora WMF Martins Fontes, 2011.

NÓBRECA, Terezinha Petrucia da. Corporeidades... Inspirações Merleau-Pontianas. NATAL: Editora Do IFRN, 2016.

NOCUEIRA,Marcia Pompeo. Ventoforte: No teatro com comunidades. Florianópolis: Letras Contemporâneas, 2015.

. Pistas para pesquisa de uma comunidade como base para um trabalho teatral. Florianópo-

lis: Teatro em comunidades. In: FLORENTINO, Adilsom; TELLES, Narciso. Cartografias do Ensino de Teatro: das ideias às práticas. Uberlândia: UDUFO, 2008a.

Teatro com meninos de rua: nos caminhos do grupo Ventoforte. São Paulo: Perspectiva,

$2008 b$ 